Article

\title{
Two Distinct Training Methods for a Doctrine of Life with Healthy Heart in a Low Socioeconomic Society Model
}

\section{Selma Metintas, Cemalettin Kalyoncu and İnci Arıkan*}

Eskisehir Osmangazi University Medical Faculty, Public Health Department 26480 Meselik-Eskisehir, Turkey; E-Mails: selmamet@ ogu.edu.tr (S.M.); kalyoncu@ogu.edu.tr (C.K.); iciarikan@hotmail.com (I.A.)

* Author to whom correspondence should be addressed; E-Mail: iciarikan@ hotmail.com; Tel.:+90-222-239-2979/45 16; Fax: +90-222-229-3049.

Received: 3 September 2009 / Accepted: 17 November 2009 / Published: 19 November 2009

\begin{abstract}
This study was conducted in three stages in a semi-rural region of Eskisehir, Turkey. In the first stage, individuals selected by random sampling were evaluated for cardiovascular disease risk factors. In the second stage, Group I and Group II training materials were randomly distributed. In the third stage, the subjects were screened one year later to assess and determine if there had been any changes in their attitudes towards the dangers of cardiovascular diseases. The number of active smokers significantly decreased after the training in the both groups. The percentage of people with regulated blood pressure exhibited an increase in Group II more than Group I.
\end{abstract}

Keywords: cardiovascular risk factors; training materials; health education; communitybased protection

\section{Introduction}

Cardiovascular disease is a very common public health issue throughout the world. Despite the decrease in cardiovascular-related disease incidence and death rates in developed countries, an increase in these indicators is being observed in developing countries due to demographic transformations and changes in lifestyle [1-4]. 
Turkey is one of several countries with a high rate of cardiovascular disease prevalence. Cardiovascular disease ranks highly among all death causes in both females and males, and the number of such deaths is expected to increase 1.8-fold in females and 2.3-fold in males by 2030 [5]. Not surprisingly, given the high prevalence of cardiovascular disease, Turkey also has a high prevalence of cardiovascular risk factors: smoking prevalence among individuals above the age of 18 is $49.4 \%$ in males and $20 \%$ in females; sedentary lifestyle prevalence is $15.9 \%$ among males and $23.6 \%$ among females; body mass index (BMI) > 30 is $9.7 \%$ and $14.5 \%$ for males and females, respectively [6,7]; and hypertension prevalence is $27.5 \%$ in males, but reportedly $36.1 \%$ in females among the population over 20 years of age [8].

The trend of decreasing incidence of cardiovascular disease in developed countries is largely due to the impact of society-based protection programs $[9,10]$. However, financial spending on programs aiming to keep cardiovascular disease under control is far lower in developing countries than in developed countries. In order to keep cardiovascular diseases under control, a salutogenic approach to developing efficient and cheap control methods is needed to decrease the risk factors [11].

A large number of cardiovascular disease intervention programs were designed to evaluate the possible effectiveness of society-based intervention $[9,10]$ to cause change in cardiovascular disease knowledge and risk-factors. These programs have used mass media health education programs, radio, television, printed media, risk factor screening, adult education classes, community-wide risk factor education campaigns at al. The programs evaluated the effectiveness of society-based interventions to modify cardiovascular disease knowledge and risk factors in developed country. However, little research has been performed on developing countries.

Another issue in developing countries is the widespread inequality in access to health care services. In order to diminish this inequality, for determining which groups have difficulty accessing health care services and in presenting relevant solutions preference should be given to groups with low socioeconomic levels.

This study aims to compare two training material formats in order to analyze the effect of distributing information about healthy heart life principles on behavioral changes in a population with a low socio-economic level.

\section{Methods}

\subsection{Study Population}

The study was conducted in a geographic areas with semi-rural characteristics, located in the Central Anatolia Region of Eskisehir. Permission for this investigation was granted by the Osmangazi University Medical Faculty Ethical Committee (Study number of Ethical Committee: 2007/381 and Clinical Trial.gov Identifier Number: NCT 00738231). In addition to its identity as a developed province of Turkey, Eskisehir is also considered to be a region with a developing rural area. As of 2006, the total population of the study region was 10,510, and the population of individuals over the age of 40 was $5,386(51.2 \%)$ [12]. The main source of income of the population is farming. The literacy rate in the region is $95 \%$. 
At the beginning of the study, the sampling volume (confidence interval $=95 \%, \alpha=5 \%, \beta=20 \%$, change rate in risk factors $=5 \%$ ) was estimated to be around 500 people. The study consisted of three stages, and was completed between September 2005 and July 2007. Since it was a follow-up study, it was started with a sampling volume that was $10 \%$ larger than the calculated volume required.

\subsection{Procedures}

In the first stage of the study, 555 individuals over 40 years of age were contacted. Individuals who were literate or had at least one literate person in the household were selected through random sampling via the records of local health care units. The average age of the individuals was $57.34 \pm 11.85$, and the gender distribution was $46.8 \%$ male and $53.2 \%$ female.

\subsection{Analytical Procedures}

The individuals were asked about their personal information, socio-demographic characteristics, and cardiovascular disease risk factors (e.g., nutritional characteristics, smoking habits, diseases diagnosed by a physician). Throughout the study period, blood pressure, weight, and height were measured. A survey of 19 questions was implemented using a scale derived from the literature that had been adapted for Turkish nationals to measure individuals' present knowledge on cardiovascular disease risk factors [13]. Answers to the questions were in the form of 'yes', 'no', and 'I do not know'. The questions included on the survey related to the following: coming to terms with having a heart disease, being aware of family predisposition, advanced age as a risk factor, smoking as a risk factor, being aware of the effects of quitting smoking, being aware of hypertension as a risk factor, knowing the effect of keeping blood pressure under control, being aware of high levels of cholesterol as a risk factor, the impact of fatty food in rising cholesterol levels, being aware of the effect of good cholesterol and bad cholesterol, knowing about weight as a risk factor, being aware that regular physical activity decreases risk, knowing that risk decreases by merely working out in the gym, being aware of diabetes as a risk factor, knowing the effect of sugar consumption in diabetes knowing the cholesterol level of diabetics, being aware of the impact of weight and blood pressure control on heart diseases in diabetics, and being aware that diabetic men have higher risk compared to diabetic women. Level of knowledge was measured by assigning a value of ' 1 ' for every affirmative answer.

Individuals who regularly smoke one or more cigarettes a day were considered to be 'smokers' [14]. With regard to nutrition, oil, fresh vegetables and fruits, red meat, and added salt consumption were also assessed. Proper nutritional behavior was defined as consuming animal fat and margarine, vegetable and fruit (at least four days per week), and red meat (at least two days per week). Additional use of salt in meals was deemed inappropriate behavior [15-18].

Physical activity levels were classified as either mild or heavy, according to literature [19]. Participant heights and weights were measured appropriately. In classifying body weight according to the Body Mass Index (BMI), individuals at $25 \mathrm{~kg} / \mathrm{m}^{2}$ and above were assessed to be overweight [20].

After completing the survey, the systolic and diastolic blood pressures were measured from the left arm of participants sitting upright, using the Korotkoff Phases 1 and 5 to acquire the measurement. In 
accordance with World Health Organization recommendations, individuals with a $140 \mathrm{mmHg}$ and above systolic blood pressure and/or with a diastolic blood pressure of $90 \mathrm{mmHg}$ and above, as well as those who were previously diagnosed with hypertension and had been taking medications, were deemed hypertensive, even if their blood pressure levels were normal at that time [21].

In the second stage of the study, public training materials about cardiovascular disease were distributed. The training materials were of two types: Group I's training material consisted of a brochure with the information we wanted the public to know about heart disease. The brochure had such titles as "Cardiovascular Diseases, let us protect our hearts, the importance of cholesterol in preventing heart diseases, watch out for blood pressure, quit smoking for your health, weight watching, nutrition, food to avoid in cardiovascular disease, an easy method: exercise and exercise control, and an appropriate body weight vs. height chart for adults" [22].

The brochure had dimensions of $21 \mathrm{~cm} \times 7.5 \mathrm{~cm}$ and included 15 small photos demonstrating various cognitive and behavioral strategies, predominantly for hypertension, hypercholesterolemia, smoking, obesity, sedentary lifestyle, and diabetes. In the brochure, the cognitive strategies identified to combat each of the risk factors consisted of increasing the level of knowledge, warning about the risks, drawing attention to the importance of the issue, and increasing understanding the benefits of keeping the risk factors under control. Among the behavioral strategies, the brochure merely showed the path to avoid risk factors and provided information about them. The Group II training material document was a letter in the form of a prescription in which the individual was addressed by name, the risk factors established at the first stage were explained, and the suggested measures for protection from such risk factors were indicated.

The training materials were randomly distributed to the study participant groups. The list of names was systematically divided into two groups: odd-numbered individuals were given brochures only, and even-numbered individuals were given both letters and brochures. Since we could not have prevented an illustrated material to be passed by in a closed environment, it was deemed appropriate to distribute both the letter and brochure instead of just the brochure.

In the second stage of the study, individuals were contacted again 15 days following distribution of the training material, and the change in their level of knowledge was investigated. The 19 same questions which the level of knowledge questionnaire from the first survey were asked again [13]. Those who reported not having read the training materials $(n=8(1.4 \%))$ were excluded from the study.

The third stage took place around a year after beginning the study. The objective of the third stage was to evaluate the effectiveness of the training materials and to determine what behavioral changes had been implemented to reduce the risk factors of coronary heart diseases. The third stage of the study consisted of a survey that was administered to 498 (89.7\%) people out of 555. Fifty-seven people who had participated in the earlier portion of the study could not be reached because they were either deceased (7), had emigrated (22), or were temporarily away from the district (28). No difference was observed between individuals who left during the follow-up and those who were able to complete the study in terms of age, gender, and socio-economic criteria $(\mathrm{p}>0.05)$. The average age of individuals who participated in the [third stage of the] study was $57.17 \pm 11.97$, of which $53.2 \%$ were females and $46.2 \%$ were males. Behavioral changes in the risk factors following the training were examined 
through the survey. Criteria adopted in the first stage were taken as the basis for evaluating the risk factors. The flow diagram of the study is given in Figure 1.

Figure 1. Flow diagram of the study.

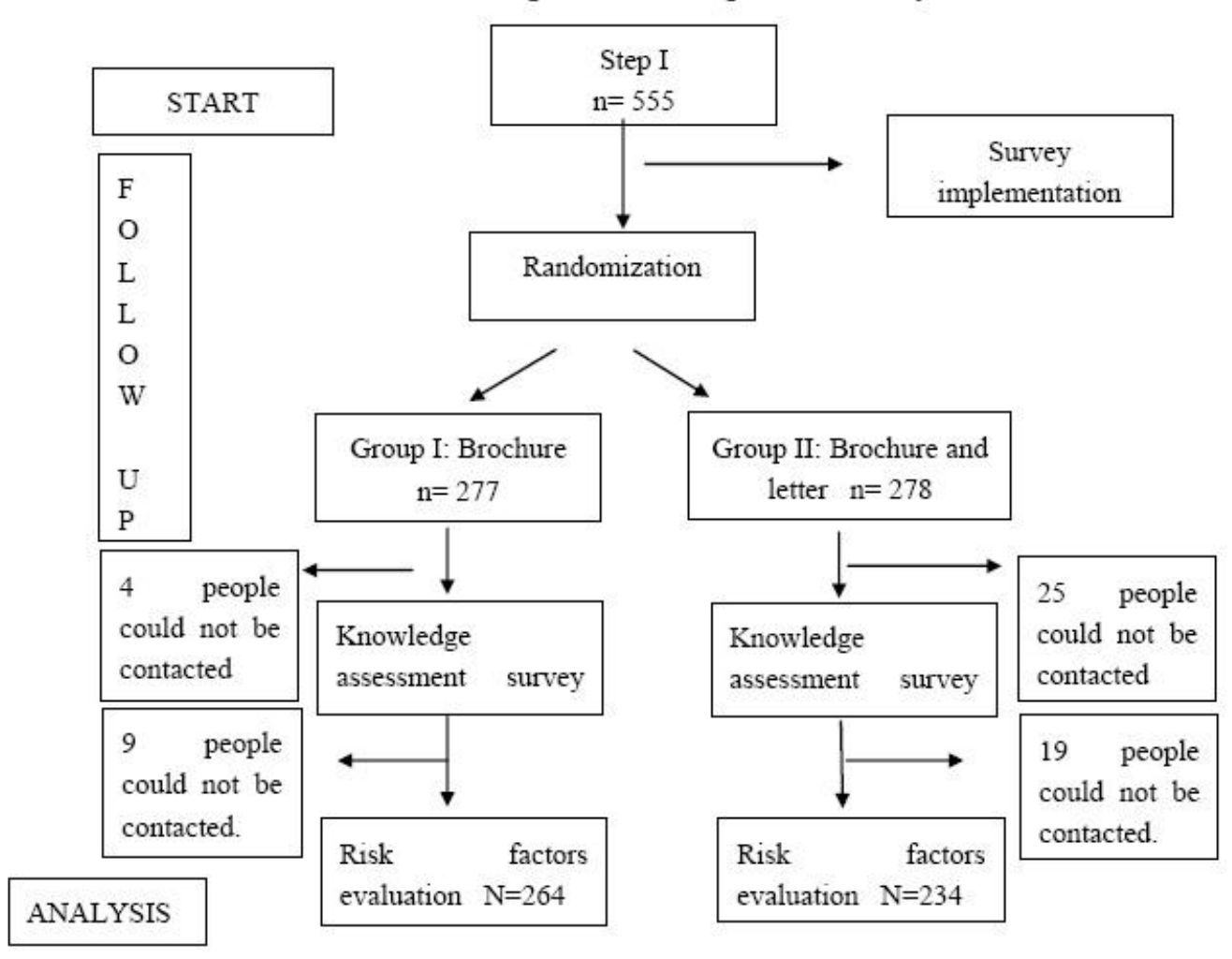

\subsection{Statistical Analyses}

Software packs were used to evaluate the data. Pearson $\mathrm{X}^{2}, \mathrm{t}$ test for dependent samples, Mc-Nemar $\mathrm{X}^{2}$, and the $\mathrm{t}$ test in matched series were applied. Linear regression was used to obtain a corrected $\mathrm{p}$ value in the analysis of the measured values, logistic regression analysis was utilized to obtain a corrected $\mathrm{p}$ value in the analysis of qualitative values.

Age, gender, education level, presence of social security, marital status, overweight status, smoking behavior, sedentary lifestyle, presence of cardiovascular disease as diagnosed by a physician, diabetes, and hypertension, were taken as the independent variables affecting the individuals that could prompt desired behavioral changes in at least one of the four parameters (being overweight, smoking, high blood pressure, sedentary lifestyle). For the single variable analyses, a logistic regression model was employed with a significance level of $\mathrm{p}<0.10$.

\section{Results}

Of the 498 people participating in all three stages of the study, 60\% were younger than $60,46.2 \%$ were females, $53.8 \%$ were males, $82.5 \%$ had less than eight years of education, $87.8 \%$ were married, and $90.2 \%$ had social security. Among the 264 people that received Group I training materials and the 234 people that received Group II training materials, no difference was observed in terms of 
socio-demographic characteristics (age groups, gender, education level, marital status, and the receipt of social security) $(\mathrm{p}>0.05)$.

Risky behaviors observed among the individuals in the study group related to the consumption of fat (29.3\%), salt (15.1\%), red meat (7\%), and insufficient consumption of vegetables and fruits $(82.7 \%)$. Physically inactive individuals comprised $20.5 \%$ of the group, $69.9 \%$ were overweight, and $30.3 \%$ were smokers. Rates for hypertension, diabetes, and diagnosis of cardiovascular disease were $46.2 \%$, $9.4 \%$ and $19.9 \%$, respectively.

The average score on the survey obtained before training was $9.51 \pm 4.68$ (min-max: 0-19), and rose to $14.01 \pm 2.99$ (min-max: 4-19) after training $(\mathrm{p}<0.001)$. Score increases were found to be significant $(\mathrm{p}<0.001)$. The score changes of individuals who were given Group I and Group II training materials were not observed to have significant differences after their adjusted for the first scores $(\mathrm{p}=0.447)$.

Figure 2. Distribution of average knowledge scores to for each set of training materials before and after the training.

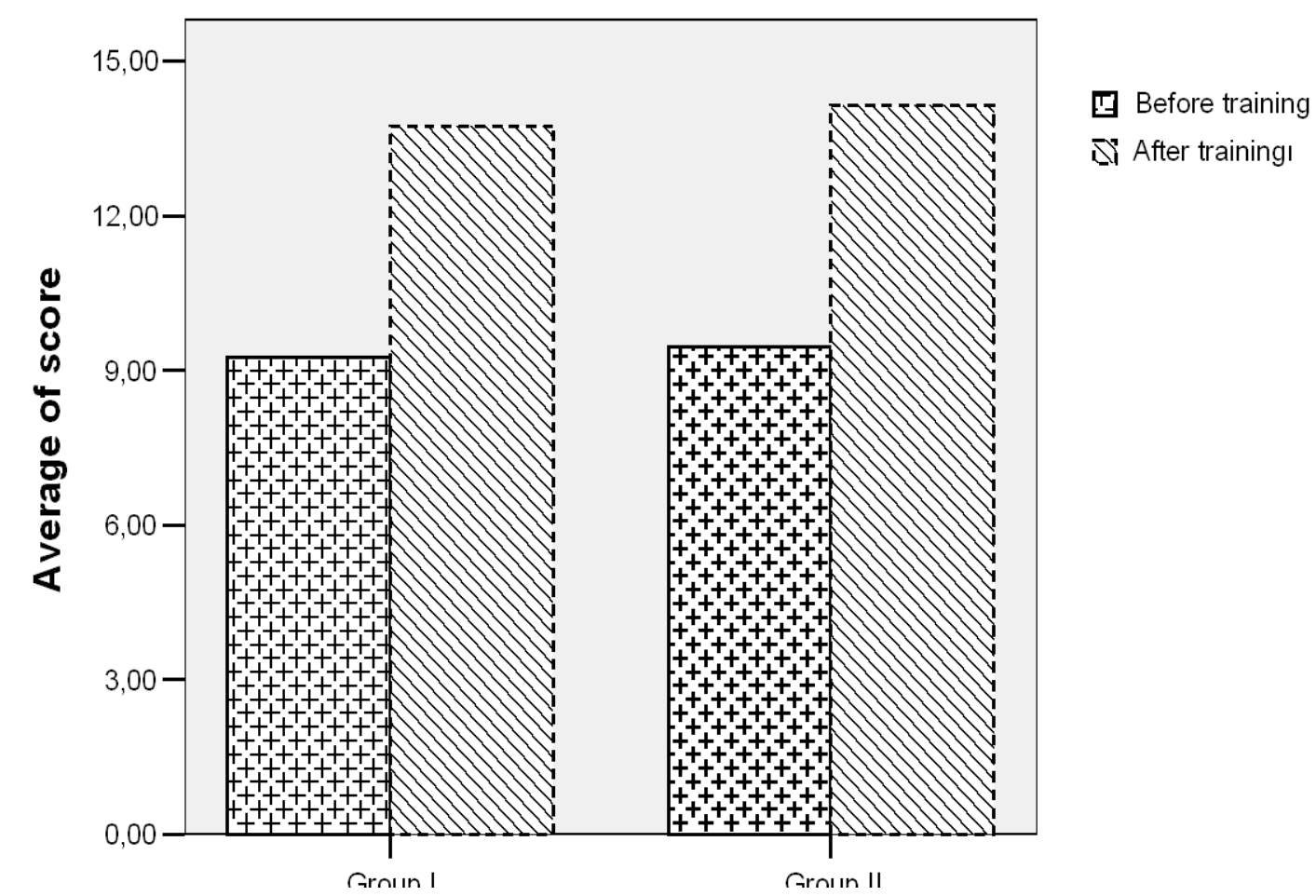

Nutritional habits exhibited significant changes after the training, except for excessive consumption of fat. The change in nutritional habits did not show any difference between the training material groups. While the most inappropriately consumed food group was vegetables and fruits, the scarcity in red meat consumption was due to an inability to obtain this food type (Table 1). 
Table 1. Before and after training change characteristics of risky nutritional habits.

\begin{tabular}{|c|c|c|c|c|c|}
\hline Variables & \multicolumn{2}{|c|}{$\begin{array}{l}\quad \text { Training material } \\
\text { Group I Group II }(\mathrm{n}= \\
\text { 264) }(\mathrm{n}=234)\end{array}$} & \multicolumn{2}{|c|}{$\begin{array}{c}\text { Analysis of } \\
\text { Change }(\mathrm{P})^{*} \\
\text { Group I Group II }\end{array}$} & \multirow[t]{2}{*}{$\begin{array}{c}\Delta \text { Group I/ } \\
\Delta \text { Group II } \\
\quad \mathrm{P}^{* *} \\
\end{array}$} \\
\hline \multicolumn{5}{|l|}{ Inappropriate fat consumption } & \\
\hline Starting value & $80(30.3)$ & $66(28.2)$ & & & 0,964 \\
\hline After the training & $72(27.3)$ & $53(22.6)$ & 0.40 & 0.105 & \\
\hline Change & -3.0 & -5.6 & & & \\
\hline \multicolumn{6}{|l|}{ Inappropriate salt consumption } \\
\hline Starting value & $41(15.5)$ & $34(14.5)$ & $<0.001$ & $<0.001$ & 0.728 \\
\hline After the training & $23(8.7)$ & $16(6.8)$ & & & \\
\hline Change & -6.8 & -7.7 & & & \\
\hline \multicolumn{6}{|l|}{$\begin{array}{l}\text { Inappropriate red meat } \\
\text { consumption }\end{array}$} \\
\hline Starting value & $27(10.2)$ & $12(5.1)$ & $<0.001$ & $<0.001$ & 0.105 \\
\hline After the training & $14(5.3)$ & $7(3.0)$ & & & \\
\hline Change & -4.9 & -2.1 & & & \\
\hline \multicolumn{6}{|l|}{$\begin{array}{l}\text { Inappropriate vegetable/fruit } \\
\text { consumption }\end{array}$} \\
\hline Starting value & $215(81.4)$ & $197(84.2)$ & $<0.001$ & $<0.001$ & 0.897 \\
\hline After the training & $156(59.1)$ & $140(59.8)$ & & & \\
\hline Change & -22.3 & -24.4 & & & \\
\hline
\end{tabular}

*: The Mc-Nemar $\mathrm{X}^{2}$ test was utilized to analyze the change that occurred after the training. **: The difference in the change between the training materials was adjusted through logistic regression based on age and gender.

A significant decrease was observed after the training in terms of systolic sand diastolic blood pressure among individuals in both groups. The decrease in systolic and diastolic blood pressure levels was $2 \mathrm{mmHg}$. A difference was not reported between the training materials in terms of efficiency (Table 2).

Table 2. Before and after training change characteristics of scalable cardiovascular risks.

\begin{tabular}{|c|c|c|c|c|c|}
\hline Variables & $\begin{array}{r}\text { Training } \\
\text { Group I Group II } \\
(\mathrm{n}=264)(\mathrm{n}=23\end{array}$ & $\begin{array}{l}\text { material } \\
\text { 4) }\end{array}$ & $\begin{array}{r}\text { An } \\
\text { Cha } \\
\text { Group }\end{array}$ & $\begin{array}{l}\text { sis of } \\
\text { e }(\mathrm{P})^{*} \\
\text { Sroup II }\end{array}$ & $\begin{array}{c}\Delta \text { Group I/ } \\
\Delta \text { Group II } \\
\mathrm{P}^{* *}\end{array}$ \\
\hline \multicolumn{6}{|l|}{ SBP mmHg } \\
\hline Starting value & $133.55 \pm 21.64$ & $134.67 \pm 19.39$ & 0.007 & 0.007 & 0.968 \\
\hline After the training & $131.93 \pm 18.30$ & $132.20 \pm 19.93$ & & & \\
\hline Change & -1.62 & -2.47 & & & \\
\hline
\end{tabular}


Table 2. Cont.

\begin{tabular}{|c|c|c|c|c|c|}
\hline \multicolumn{6}{|l|}{ DBP } \\
\hline Starting value & $84.13 \pm 12.58$ & $85.06 \pm 13.15$ & 0.001 & 0.005 & 0.960 \\
\hline After the training & $82.65 \pm 11.33$ & $83.59 \pm 13.56$ & & & \\
\hline Change & -1.48 & -1.47 & & & \\
\hline \multicolumn{6}{|l|}{ Weight (kg) } \\
\hline Starting value & $73.12 \pm 12.99$ & $74.56 \pm 11.88$ & 0.678 & 0.090 & 0.457 \\
\hline After the training & $72.89 \pm 12.96$ & $73.59 \pm 12.54$ & & & \\
\hline Change & -0.23 & -0.97 & & & \\
\hline \multicolumn{6}{|l|}{ BMI $\left(\mathrm{kg} / \mathrm{m}^{2}\right)$} \\
\hline Starting value & $27.60 \pm 4.81$ & $28.27 \pm 4.81$ & 0.427 & 0.010 & 0.184 \\
\hline After the training & $27.55 \pm 4.96$ & $27.83 \pm 5.11$ & & & \\
\hline Change & -0.05 & -0.44 & & & \\
\hline
\end{tabular}

*: In the analysis of the change that occurred after the training, the p value was adjusted based on pretraining values and calculated with linear regression. **: $\mathrm{p}$ value of the difference between the training materials adjusted using pre-training values and calculated with linear regression. SBP: Systolic blood pressure, DBP: Diastolic blood pressure, BMI: Body Mass Index.

The blood pressure levels decreased in 6.5\% ( $\mathrm{p}=0.10)$ of individuals who were given Group I training materials, and in $12.4 \%(\mathrm{p}=0.003)$ of individuals who were given Group II training materials. Among those who were given Group II training materials, arterial blood pressure regulation after the training was found to have significantly increased.

Though not significant, the weights of individuals with Group II training material manifested a decrease $(\mathrm{p}=0.090)$. Only individuals who were given the Group II training material had a significant drop in BMI after the training (Table 2).

The number of active smokers who were given either Group I or Group II training materials showed a significant decrease after the training (Table 3).

Table 3. Before and after training changes in cardiovascular risk factors.

\begin{tabular}{|c|c|c|c|c|c|}
\hline Variables & \multicolumn{2}{|c|}{$\begin{array}{l}\text { Training material } \\
\text { Group I Group II } \\
(\mathrm{n}=264)(\mathrm{n}=234)\end{array}$} & \multicolumn{2}{|c|}{$\begin{array}{c}\text { Analysis of } \\
\text { Change }(\mathrm{P})^{*} \\
\text { Group I Group II }\end{array}$} & \multirow[t]{2}{*}{$\begin{array}{c}\Delta \text { Group I/ } \\
\Delta \text { Group II } \\
\text { P** }\end{array}$} \\
\hline Sedentary lifestyle rate & & & & & \\
\hline Starting value & $61(23.1)$ & $41(17.5)$ & 0.182 & 0.576 & 0.765 \\
\hline After the training & $49(18.6)$ & $36(15.4)$ & & & \\
\hline Change & -4.5 & -2.1 & & & \\
\hline \multicolumn{6}{|l|}{ Rate of regulated TA } \\
\hline Starting value & $114(43.2)$ & $119(50.9)$ & 0.100 & 0.003 & 0.549 \\
\hline After the training & $97(36.7)$ & $90(38.5)$ & & & \\
\hline Change & -6.5 & -12.4 & & & \\
\hline
\end{tabular}


Table 3. Cont.

Rate of $\mathrm{BMI}>25$

$\begin{array}{rccccc}\text { Starting value } & 180(68.2) & 168(71.8) & 0.892 & 0.268 & 0.806 \\ \text { After the training } & 178(67.4) & 160(68.4) & & & \\ \text { Change } & -0.8 & -3.4 & & & \end{array}$

Active smoker rate

$\begin{array}{rlllll}\text { Starting value } & 82(31.1) & 71(30.4) & 0.004 & 0.002 & 0.624 \\ \text { After the training } & 69(26.2) & 53(22.7) & & & \end{array}$

*: The Mc-Nemar $\mathrm{X}^{2}$ test was utilized to analyze the change occurred after the training. **: Difference in change between the training materials was adjusted using logistic regression based on age and gender.

In the third stage of the study, 182 people $(36.5 \%)$ were identified to have manifested a change in at least one of the four risky behaviors. In establishing effective variables concerning positive behavioral changes, it was not possible to identify significant effects of gender $(\mathrm{p}=0.583)$, social security intake $(\mathrm{p}=0.733)$, marital status $(\mathrm{p}=0.841)$, cardiovascular disease diagnosis $(\mathrm{p}=0.813)$, diabetes diagnosis of $(\mathrm{p}=0.708)$, and smoking habits $(\mathrm{p}=0.627)$.

There was no effect of the level of score change on the behavioral change $(p=0.144)$. Age, training period, hypertension, physical activity, and weight were included in the logistic model used to determine the independent variables affecting positive behavioral changes. It was not possible to judge the effect of education level and overweight status on the positive behavioral change. The positive impact from the training increased values 1.6 times with age over 60 years, 4.5 times in people with hypertension, and 8.7 times in people who were physically sedentary (Table 4).

Table 4. Logistic model showing the effect of independent variables on behavioral changes.

\begin{tabular}{|c|c|c|c|c|}
\hline Variables & $\begin{array}{l}\text { Rate of people } \\
\text { showing } \\
\text { changes }(\%)\end{array}$ & OR & $\% 95 \mathrm{CI}$ & $\mathrm{P}$ \\
\hline \multicolumn{5}{|l|}{ Age } \\
\hline Below 60 & 28.4 & 1 & & \\
\hline 60 and above & 48.7 & 1.611 & $1.039-2.498$ & 0.033 \\
\hline \multicolumn{5}{|l|}{$\begin{array}{l}\text { Period of } \\
\text { education }\end{array}$} \\
\hline 8 years or less & 37.3 & 1 & & \\
\hline 8 and above & 32.9 & 1.134 & $0.634-2.031$ & 0.671 \\
\hline \multicolumn{5}{|l|}{ Hypertension } \\
\hline No diagnosis & 22.8 & 1 & & \\
\hline With diagnosis & 52.6 & 4.569 & $2.921-7.147$ & 0.000 \\
\hline \multicolumn{5}{|l|}{ Physical activity } \\
\hline Active & 27.0 & 1 & & \\
\hline Sedentary & 73.5 & 8.778 & $5.055-15.244$ & 0.000 \\
\hline \multicolumn{5}{|l|}{$\mathrm{BMI}>25$} \\
\hline Non-overweight & 34.0 & 1 & & \\
\hline Overweight & 37.6 & 1.154 & $0.714-1.865$ & 0.559 \\
\hline
\end{tabular}




\section{Discussion}

Advances in social principle theories and behavioral change theory models have determined the course of specific cognitive and behavioral processes in encouraging appropriate behavioral changes in health. Behavioral changes are second to cognitive changes in terms of which type of changes should take priority [13].

Studies on controlling cardiovascular risks are plentiful, with national media campaigns, training materials, conferences, behavior change-specific programs, and public march programs being examined. It is a known fact in many countries that public health training endeavors related to cardiovascular diseases expand the awareness and knowledge of risk factors [24-26]. In order to avoid many risk factors, it was shown that willingness to participate increases the likelihood of the individual starting the activity [22].

Apart from the fact that education efforts increase knowledge, awareness, and willingness to adopt behavior changes, it is necessary for the knowledge to be transformed into healthy behavior. There is a need for studies to find methods to stimulate this transformation. The objective of this study was to compare the two sets of training materials prepared in order to analyze the effect of the information presentation format.

It was observed that, in groups with low socio-economic and education levels that had more difficulty accessing information, the studies produced more successful results. The geographic area in which the present study was implemented is an example of such a region. The study adopted the individual interview method of community-based protection programs. First, the risk factors of the individuals were analyzed, and their awareness of the risk factors was expanded through verbal dialogue. Then, they received the training materials. Group II training materials addressed the individuals by name, explained what should be done regarding the cardiovascular risk factors unique to each person, and were designed in the fashion of a prescription.

As is the case in many studies, our data showed no significant problems with presenting the information [27-29]. The survey used examined the participant's level of knowledge about the risk factors, and the number of correct answers was quite satisfactory after the training. A difference was not observed between the training materials in terms of their ability to increase the individual's level of knowledge.

Today, it is known that unhealthy nutrition has a negative effect on cardiovascular disease. Consumption of food with high saturated fat levels, high levels of salt, large amounts of carbohydrates, and excessive consumption of red meat are among the examples of unhealthy nutritional behaviors. Since regular consumption of food rich in fiber such as fruits, vegetables and grains are known to have a preventive effect, insufficient intake of these products constitutes a risk for cardiovascular disease.

In studies analyzing the effects of diet and implementing an aggressive limitation of fat intake, a roughly 30 to 60 percent decrease in deaths was observed [30]. However, the desired significant change regarding fat use was not observed though a positive change in overall nutritional habits was obtained after the training. In fact, the type of fat used by a given household is an established habit and behavior pattern, and is also a function of the economic status of the family. Solid fats like margarine are cheap, whereas olive oil is expensive. 
In a study conducted by Cutler et al. on limiting salt intake, it was reported that a $50 \%$ decrease in the salt intake could probably result in a significant drop in high blood pressure [31]. In the study, individuals who consumed appropriate amounts of salt manifested a 7.25\% decrease in blood pressure; this drop was not due to salt added to meals during cooking, but rather to the amount of salt added to meals after cooking. Limiting salt intake is not a practice generally adopted by the public, except hypertension patients.

The results obtained concerning red meat consumption were not different from the pre-training results. In the group with low red meat consumption (due to economic constraints), only $3.5 \%$ of participants' scores related to appropriate meat consumption were affected.

Although a significant increase of $23.35 \%$ was obtained for vegetable and fruit consumption after the training, the level of vegetable and fruit consumption in the study group was still lower than desirable.

According to Framingham Coronary Profile Risk Factor Scoring, cardiovascular disease risk was reported to have shown a 15\% drop due to an increase in participant physical activity [32]. Also, it was reported in a TEKHARF Study (Turkish Adults Risk Factor Study) carried out in Turkey that, through regular and appropriate exercise, a 23 percent decrease in deaths due to cardiovascular diseases was seen [33]. Similarly, in a study conducted to determine the physical activity levels of women in Croatia, the physical activity level among housewives below the age of 50 was reported to be low, but the activity level increased with patient participation in appropriate supportive programs [34].

Although it is a known fact that physical activities have positive effects on health, it is difficult to bring about a change in behavior that encourages increasing the level of physical activity of individuals. Although working out might be known to improve health, only a very small portion of the adult population, most of which are of a higher education level, participate in such activities [35,36].

A change in one's level of physical activity would impact most of the cardiovascular risk factors and create significant changes in the blood lipid profile, hypertension, and body composition. The most important reason why we were not able to obtain the expected level of success in terms of physical activity in our study was the lack of locations to carry out outdoor activities within the geographic region where our study was conducted. From a cultural point of view, a woman living in a rural area does not leave the house very often, nor does she have a habit of walking regularly (apart from her housework). Also, men in rural areas tend to spend their time gathering in coffee houses, especially in the winter. It would thus be appropriate to develop social support policies in addition to providing information on an individual basis concerning the need to increase physical activity.

A significant decrease $(2.1 \%)$ in the number of individuals with a BMI > 25 was not observed after the training. A $2.1 \%$ drop was observed in the overweight group after the training. It is clear that the dietary habits of people can change, but a decrease in BMI is only possible through systematic, longterm health education supplemented with behavioral change strategies [23]. In situations where we were not able to inspire an increase the physical activity level, we should have expected a change in BMI as a result of changes in the nutritional habits. A primary prevention study on obesity is complicated by variations in genetic predisposition, and many risk factors known for cardiovascular disease have a wider-reach than strictly behavior [23]. 
One of the most positive effects, in terms of lifestyle, manifested itself in the participants' systolic and diastolic blood pressures. Around a $2 \mathrm{~mm} \mathrm{Hg}$ drop in systolic and diastolic blood pressure was observed after the training. The rate of regulated blood pressure among the individuals who were given Group II training materials was observed to have a significant increase. In our region, where the number of people with ideal blood pressure levels is quite high, the fact that successful results were obtained with minimal effort should prove informative for future studies. As a result of a research program by Kisioglu et al. that incorporated training on how to better control high blood pressure among middle-aged women of low socio-economic level in Isparta, hypertension prevalence was reported to decrease [37].

Smoking is an important public health issue in Turkey and in the rest of the world. Although the number of smokers in developed countries has been decreasing since the seventies, it has shown an increase in developing countries. As a result of training programs and other measures taken against smoking, 36 million people in the USA, 8 million people in France, and 1 million people in Switzerland have quit smoking [38].

According to the results obtained from the TUMAR (Multi-centered Turkish Myocardial Infarction Study) in Turkey, the number of smokers was reported to be 17 million [33]. In a EURO-ASPIRE III study, the population of Turkey was reported to have the highest probability of individuals below the age of 50 having myocardial infarction (relative to 22 European countries). The prevalence of smoking plays an important role in this finding [39]. A 6.3\% decrease in active smoking occurred in the study. Considering that quitting smoking is a difficult and lengthy process, it is quite an achievement that this outcome was obtained in such a short period of time.

Among the 182 people (36.5\%) manifesting a change in at least one of four risky behaviors (namely losing weight, quitting smoking, regulating blood pressure, and increasing physical activity), individuals who were above the age of 60 years, diagnosed with hypertension, and/or, leading sedentary lifestyles were observed to be more positively affected by the training.

However, it is more important to have younger groups adapt healthy lifestyles it takes a long time for disease to develop. An immediate decrease in the amount of contact with risk factors would reduce the risk of cardiovascular disease. The fact that behavioral changes in individuals with sedentary lifestyles occurred at rates 8.7 times higher than those of physically active individuals, despite our inability to achieve the desired training success in the group of people with sedentary lifestyles, might be due to the fact that individuals were unable to adapt to changing such risk factors as quitting smoking and losing weight. The number of behavioral changes that occurred in individuals diagnosed with hypertension suggests a future training group that could yield immediate results.

Although there was no difference between the Group I and Group II training materials for many parameters of the study, the Group II training material proved to be superior for controlling blood pressure. We thus deem use of this material to be a method for implementing a salutogenic approach, whereby a human assumes a healthy lifestyle through the best utilization of his unique opportunities. The aim of preparing the Group II training material was to enable the individual to see his or her risks as unique, and to proceed with life by adapting personal behaviors. The Group II training material document was the same brochure by Group I and a letter in the form of a prescription. This letter was a 
more remarkable because it has appealed to people. On the other hand Turkish people like to get a prescription from a doctor.

\section{Conclusions}

One of the most significant disadvantages of community-based training programs is the low success rate. As a matter of fact, it might be difficult to truthfully determine the effect of changing individual risk factors on health outcomes. A drop in the risks for cardiovascular disease could be more attributable to decreases in blood cholesterol level, blood pressure, and BMI. When more than one change in behaviors is observed in the same individual, a multiplied decrease would occur in morbidity and mortality [24]. Because of the prevalence of unhealthy behaviors in risk factors in all societies, small changes could produce significant health effects.

This study demonstrated that while an individual's knowledge about certain risk factors might increase, one can expect only limited success with inspiring lifestyle changes (aside: we recognize that the training implemented here was little more than a crude scaling tool). However, we can conclude that social programs oriented towards individual behavioral changes assume an important role in decreasing cardiovascular risk factors.

\section{References}

1. Levenson, J.W.; Skerret, P.J.; Gaziano, J.M. Reducing the global burden cardiovascular disease: the role of risk factors. Prev. Cardiol. 2002, 5, 188-199.

2. The World Health Report 2002. Available online: http://www.who.int/whr/2002/en/links.html (accessed October 9, 2007).

3. Gaziano, T.A. Reducing the growing burden of cardiovascular disease in the developing world. Health Affairs 2007, 26, 13-23.

4. Nissinen, A.; Berrios, X.; Puska, P. Community-based noncommunicable disease interventions: lessons from developed countries for developing ones. Bull. World Health Organ. 2001, 79, 963-970.

5. The Ministry of Health of Turkey. Health at a Glance Turkey 2007; The Ministry of Health of Turkey Refik Saydam Hygiene Center Presidency School of Public Health Press: Ankara, Turkey, 2007; pp. 7-15.

6. The Ministry of Health of Turkey. Turkey Disease Load Study 2004; Aydoğdu Ofset Press: Ankara, Turkey, 2006; pp. 12-20.

7. Onat, A. Risk factors and cardiovascular disease in Turkey. Atherosclerosis 2001, 156, 1-10.

8. Altun, B.; Arıcı, M.; Nergizoğlu, G.; Derici, U.; Karatan, O.; Turgan, C.; Sindel, S.; Erbay, B.; Hasanoğlu, E.; Çağlar, S.; for the Turkish Society of Hypertension and Renal Diseases. Prevalence, awareness, treatment and control of hypertension in Turkey (The Patent Study) in 2003. J. Hypertens. 2005, 23, 817-823.

9. Ônpuu, S.; Negassa, A.; Yusuf, S. INTER-HEART: A global study of risk factors for acute myocardial infarction. Am. Heart J. 2001, 141, 711-721. 
10. Atienza, A.A.; King, A.C. Community-based health intervention trials: An overview of methodological issues. Epidemio. Rev. 2002, 24, 72-79.

11. Judd, J.; Frankish, C.J.; Moulton, G. Setting standards in the evaluation of community-based health promotion programmes--a unifying approach. Health Promot. Int. 2001, 16, 367-380.

12. Eskişehir Health Department. Statistical data of Eskişehir Health Department 2006. Available online: http://www.eskisehirsaglik.gov.tr/statistics (accessed July 5, 2007).

13. Wagner, J.; Lacey, K.; Chyun, D.; Abbott, G. Development of a questionnaire to measure heart disease risk knowledge in people with diabetes: the heart disease fact questionnaire. Patient Educ. Couns. 2005, 58, 82-87.

14. WHO Policy on Non-Recruitment of Smokers or Other Tobacco Users. Available online: http://www.who.int/employment/FAQs_smoking_English.pdf (accessed October 9, 2007).

15. Bassuk, S.S.; Manson, J.E. Lifestyle and Risk of Cardiovascular Disease and Type 2 Diabetes in Women: A Review of the Epidemiologic Evidence. Am. J. Lifestyle Med. 2008, 2, 191-213.

16. Burke, V.; Zhao, Y.; Lee, A.H.; Hunter, E.; Spargo, R.M.; Gracey, M.; Smith, R. Hospital admissions and length of stay for coronary disease in an Aboriginal cohort. Nutr. Metab. Cardiovasc. Dis. 2008, 18, 357-364.

17. Fung, T.T.; Willett, W.C.; Stampfer, M.J.; Manson, J.E. Dietary patterns and the risk of coronary heart disease in women. Arch. Intern. Med. 2001, 161, 1857-1862.

18. Fodor, G.J.; Whitmore, B.; Leenen, F.; Larochelle, P. Recommendations on dietary salt. CMAJ 1999, 160, 29-34.

19. Hu, G.; Tuomilehto, J.; Silventoinen, K.; Barengo, N.; Jousilahti, P. Joint effects of physical activity, body mass index, waist circumference and waist-to-hip ratio with the risk of cardiovascular disease among middle-aged Finnish men and women. Eur. Heart J. 2004, 25, 2212-2219.

20. Body Mass Index (BMI). World Health Organization Regional Office for Europe: Copenhagen, Denmark; Available online: http://www.euro.who.int/nutrition/20030507_1 (accessed December 19, 2006).

21. European Society of Hypertension-European Society of Cardiology Guidelines Committee. European Society of Hypertension-European Society of Cardiology guidelines for the management of arterial hypertension, 2003. J. Hypertens. 2003, 21, 1011-1053.

22. Metintaş, S.; Arıkan, İ. Kalp Damar Hastalıklarından Korunma Broşürü; ESOGÜ Press: Eskisehir, Turkey, 2006.

23. Weinehall, L.; Hellsten, G.; Boman, K.; Hallmans, G. Prevention of cardiovascular disease in Sweden: The NORSJO community intervention programme: motives, methods and intervention components. Scand. J. Public Health 2001, 29, 13-20.

24. Vartiainen, E.; Jousilahti, P.; Alfthan, G.; Sundvall, J.; Pietinen, P.; Puska, P. Cardiovascular risk factor changes in Finland,1972-1997. Int. J. Epidemiol. 2000, 29, 49-56.

25. Fortmann, S.P.; Varady, A.N. Effects of a community-wide health education program on cardiovascular disease morbidity and mortality. Am. J. Epidemiol. 2000, 152, 316-323.

26. Merzel, C.; Afflitti, D.J. Reconsidering community-based health promotion: Promise, performance and potential. Am. J. Public Health 2003, 93, 557-574. 
27. PREMIER Collaborative Research Group: Effects of comprehensive lifestyle modification on blood pressure control. Main Results of the PREMIER Clinical Trial. JAMA. 2003, 289, 2083-2093.

28. Gans, K.M.; Assmann, S.F.; Sallar, A.; Lasater, T.M. Knowledge of cardiovascular disease prevention: An analysis from two New England Communities. Prev. Med. 1999, 29, 229-237.

29. Margellos-Anast, H.; Estarziau, M.; Kaufman, G. Cardiovascular disease knowledge among culturally Deaf patients in Chicago. Prev. Med. 2006, 42, 235-239.

30. Howard, B.V.; van Horn, L.; Hsia, J.; Manson, J.E.; Stefanick, M.L.; Wassentheil-Smoller, S.; Kuller, L.H.; LaCroix, A.Z.; Langer, R.O.; Lasser, N.L.; et al. Low-fat dietary pattern and risk of cardiovascular disease. The Women's health initiative randomized controlled dietary modification trial. JAMA 2006, 295, 655-666.

31. Cutler, J.A.; Follmann, D.; Allender, P.S. Randomized trials of sodium reduction: an overview. Am. J. Clin. Nutr. 1997, 65, 643-651.

32. Hu, G.; Tuomilehto, J.; Borodulin, K.; Jousilahti, P. The joint associations of occupational, commuting, and leisure-time physical activity, and the Framingham risk score on the 10-year risk of coronary heart disease. Eur. Heart J. 2007, 28, 492-498.

33. Basic Principles of National Health of Heart (Turkey). Available online: http://www.tkd.org.tr (accessed September 10, 2007).

34. Misigoj-Duraković, M.; Heimer, S.; Matković, B.R.; Ruzić, L.; Prskalo, I. Physical activity of urban adult population: questionnaire study. Croat. Med. J. 2000, 41, 428-432.

35. Halm, M.A.; Denker, J. Primary prevention programs to reduce hearth disease risk in women. Clin. Nurse. Spec. 2003, 17, 101-109.

36. Lupton, B.S.; Fønnebø, V.; Søgaard, J. The Finmark Intervention study: is it possible to change CVD risk factors by community-based intervention in an Arctic village in crisis? Scand. J. Public Health 2003, 31, 178-186.

37. Kisioglu, A.N.; Aslan, B.; Ozturk, M.; Aykut, M.; İlhan, I. Improving control of high blood pressure among middle-aged Turkish women of low socio-economic status though public health training. Croat. Med. J. 2004, 45, 477-482.

38. World Bank. Curbing the Epidemics: Governments and the Economics of Tobacco Control; The World Bank: Washington, DC, USA, 1999.

39. Tokgözoğlu, L. 'EUROASPIRE'. Available online: http://www.tkd.org.tr/euroaspire.html (accessed September 10, 2008).

(C) 2009 by the authors; licensee Molecular Diversity Preservation International, Basel, Switzerland. This article is an open-access article distributed under the terms and conditions of the Creative Commons Attribution license (http://creativecommons.org/licenses/by/3.0/). 